\title{
Ocular cicatricial pemphigoid masquerading as chronic conjunctivitis: a case report
}

This article was published in the following Dove Press journal:

Clinical Ophthalmology

13 December 2012

Number of times this article has been viewed

\section{Joanna DaCosta}

Moorfields Eye Hospital, London, UK
Correspondence: Joanna DaCosta Moorfields Eye Hospital, 162 City Road, London ECIV 2PD, UK

Tel +44207253 34II

Fax +442072534696

Email joanna.dacosta@moorfields.nhs.uk
Abstract: Conjunctivitis is often considered an innocuous condition which is self-limiting. This report describes misdiagnosis of ocular cicatricial pemphigoid as chronic conjunctivitis. Ocular cicatricial pemphigoid is a rare autoimmune condition. The clinical features which are useful to distinguish this condition from infective conjunctivitis are discussed. The investigation and treatment of ocular cicatricial pemphigoid is discussed. It is important to recognize nonocular symptoms and signs that may indicate the presence of a more serious underlying pathological condition necessitating specialized ophthalmic referral and subsequent investigation and treatment.

Keywords: autoimmune, conjunctivitis, ocular cicatricial pemphigoid

\section{Case report}

A 70-year-old male presented with a 10-week history of bilateral red eyes with a mucoid discharge. The ocular symptoms were associated with a sore throat over the preceding 6 weeks. He had been seen and treated unsuccessfully by his general practitioner, local accident and emergency department, and also the ophthalmic trainee.

On examination, vision was $6 / 9$ on the right and 6/5 on the left. He had a right lower-lid entropion and symblepharon. The conjunctiva was chemosed bilaterally, with loss of contour of the caruncle, and partial obliteration of the fornix (Figure 1). The cornea showed a bilateral epitheliopathy. Hard- and soft-palate ulceration was present (Figure 2). No skin lesions were apparent.

Investigation results showed a normal full blood count, urea and electrolytes, erythrocyte sedimentation rate, C-reactive protein, and no bacterial growth from a conjunctival swab. He underwent initial hard-palate biopsy, which was immunocytochemistry negative and revealed a mucopurulent exudate. Diagnosis was subsequently confirmed with conjunctival biopsy. Treatment was instituted with oral prednisolone, topical dapsone and chloramphenicol, and prednisolone eye drops. With this treatment, his symptoms resolved and the lid changes remained stable with no progression.

\section{Discussion}

Ocular cicatricial pemphigoid (OCP) involves the conjunctiva in the majority of cases and causes progressive cicatrization. It is a rare condition and the diagnosis may be overlooked in the early stages, hence the true incidence may be underestimated. Incidence rates vary between one in 12,000 to one in $60,000{ }^{1}$ 


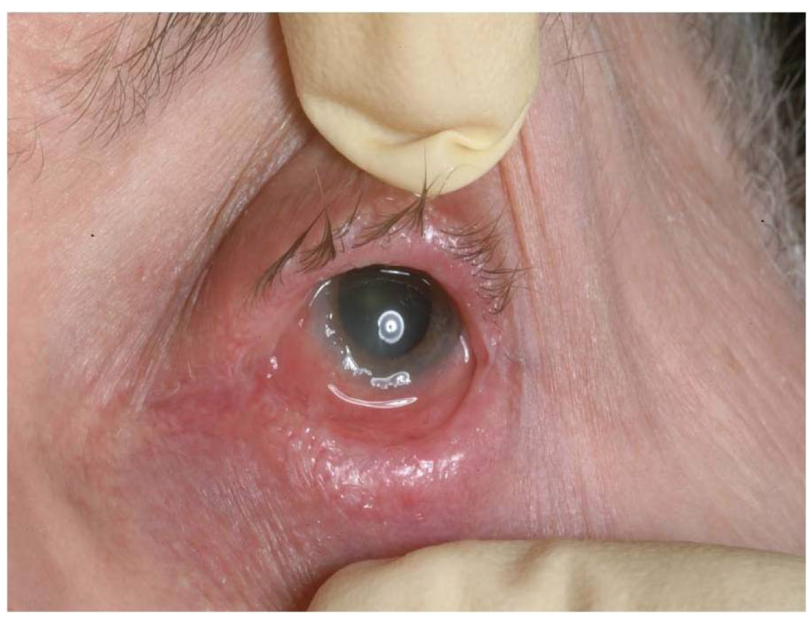

Figure I Conjunctival chemosis, loss of contour of the caruncle, and shortening of the fornix.

The pathogenesis of the condition is not completely understood. OCP has been described as a type II immune reaction characterized by the deposition of immunoreactants (immunoglobulin G, immunoglobulin A, immunoglobulin $\mathrm{M}$, and/or complement) along the epithelial basement membrane zone. One particular antigen, the $\beta 4$ subunit of $\alpha 6 \beta 4$ integrin, has been identified as the target in the basement membrane zone of the conjunctiva and epidermis for the immune reaction in OCP. ${ }^{2}$ Autoantibodies are produced against a variety of adhesion molecules in the hemidesmosome-epithelial membrane complex. Production of proinflammatory cytokines stimulates migration of lymphocytes, eosinophils, neutrophils, and mast cells to the basement membrane. Fibroblast activation interferes with collagen production, eventually resulting in cicatricial changes in the conjunctiva. The resulting fibrotic changes cause dry eye, meibomian

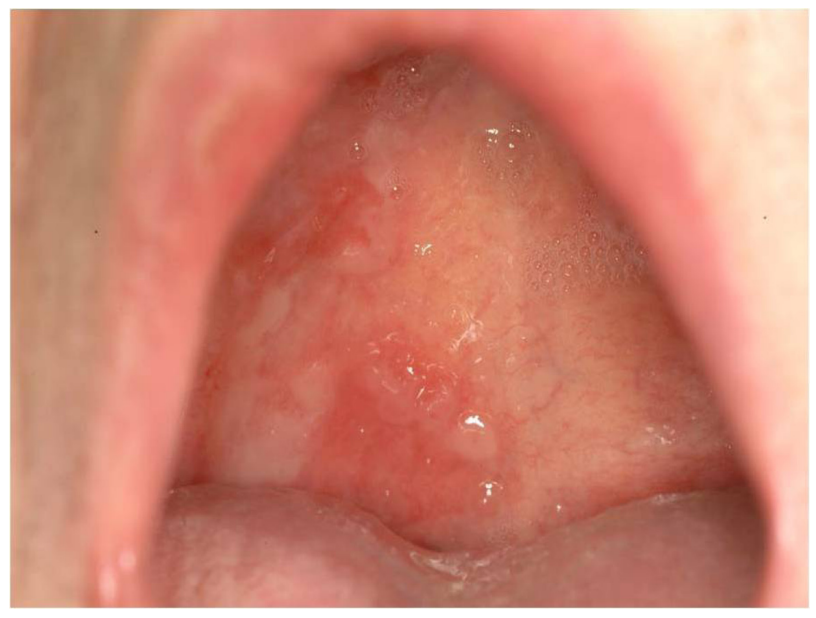

Figure 2 Hard-palate ulceration. gland dysfunction, trichiasis, persistent corneal epithelial defects, and corneal scarring.

Management, prognosis, and treatment depend on the extent of the condition. Sequential photographs are useful to monitor the disease progression. The Foster classification system relies on the clinical progression of disease (Table 1). ${ }^{3}$

In advanced cases, corneal involvement manifest by keratopathy with persistent epithelial defects, stromal ulceration, and neovascularization may lead to secondary microbial keratitis with perforation and endophthalmitis.

The definitive diagnosis requires demonstration of immunoglobulin or complement deposition at the epithelial basement membrane of biopsied conjunctiva. A negative biopsy does not exclude OCP. Repeat biopsy should include more sensitive immunoperoxidase staining with supplemental avidin-biotin complex methodology. ${ }^{4}$ The differential diagnosis includes infective conjunctivitis such as that caused by adenovirus, systemic disorders such as systemic lupus erythematosus, and Wegener's granulomatosis, side effects from topical ocular medications such as pilocarpine, trauma caused to the ocular surface from chemical or thermal burns, or multiple surgical procedures. ${ }^{5-7}$ Mucocutaneous disorders such as acne rosacea, Stevens-Johnson syndrome, and atopy may simulate the clinical signs of OCP. ${ }^{6}$

The treatment of the condition should address both the systemic immune response and local ocular sequelae of the condition.

Topical treatment includes preservative-free artificial tear replacements, topical antibiotics, and steroids. The surgical management of lid conditions such as trichiasis and entropion is best considered when the disease is quiescent as surgical manipulation of the conjunctival surface may promote progression of cicatrization. Systemic treatment is best managed by a physician as immunomodulatory treatment necessitating frequent blood test monitoring is often necessary. Dapsone is a synthetic sulfone first used in the treatment of leprosy in the 1940s. Its antiinflammatory action is thought to be mediated by stabilizing lysosomal membranes, decreasing the release of proteolytic enzymes,

Table I Foster classification of ocular cicatricial pemphigoid

\begin{tabular}{ll}
\hline Stage & Clinical features \\
\hline 1 & Chronic conjunctivitis with subepithelial fibrosis \\
2 & Shortening of inferior fornix \\
3 & Symblepharon formation \\
4 & End-stage ocular cicatricial pemphigoid, surface keratinization, \\
& complete obliteration of fornix, corneal vascularization \\
\hline
\end{tabular}


and by the inhibition of the myeloperoxidase-mediated cytotoxic system in neutrophils. ${ }^{8}$ Dapsone has been shown to halt the progression of fibrosis in $\mathrm{OCP}^{9}$ and is of use in patients confirmed not to be glucose-6-phosphate dehydrogenase deficient. Azathioprine has been shown to be effective as an adjunctive agent in OCP. ${ }^{10}$ The use of immunosuppressive therapy is of use as steroid sparing agents avoid the well-recognized long-term side effects of oral steroids.

\section{Conclusion}

This case demonstrates the importance of asking patients about nonocular symptoms when considering different diagnoses in nonresolving conjunctivitis and also the importance of examining the lids and conjunctiva which can reveal symblepharon formation. Changes such as symblepharon are of value in distinguishing a simple infective conjunctivitis from chronic cicatrizing changes, which may suggest a chronic multisystem condition. Any atypical nonresolving conjunctivitis with lid changes warrants specialized ophthalmic referral.

\section{Disclosure}

The author reports no conflicts of interest in this work.

\section{References}

1. Foster CS. Cicatricial pemphigoid. In: Krachmer JH, Mannis MJ, Holland EJ, editors. Cornea. Volume One: Fundamentals, Diagnosis and Management, 3rd ed. Philadelphia, PA: Mosby Elsevier; 2011:591-599.

2. Tyagi S, Bhol K, Natarajan K, Livir-Rallatos C, Foster CS, Ahmed AR. Ocular cicatricial pemphigoid antigens: partial sequence and characterization. Proc Natl Acad Sci U SA. 1996;93(25):14714-14719.

3. Foster CS, Wilson LA, Ekins MB. Immunosuppressive therapy for progressive ocular cicatricial pemphigoid. Ophthalmology. 1982;89(4): 340-353.

4. Ahmed M, Zein G, Khawaja F, Foster CS. Ocular cicatricial pemphigoid: pathogenesis, diagnosis and treatment. Prog Retin Eye Res. 2004;23(6): 579-592.

5. Hammer LH, Perry HD, Donnenfeld ED, Rahn EK. Symblepharon formation in epidemic keratoconjunctivitis. Cornea. 1990;9(4): 338-340.

6. Kirzhner M, Jakobiec FA. Ocular cicatricial pemphigoid: a review of clinical features, immunopathology, differential diagnosis, and current management. Semin Ophthalmol. 2011;26(4-5):270-277.

7. Jordan DR, Zafar A, Brownstein S, Faraji H. Cicatricial conjunctival inflammation with trichiasis as the presenting feature of Wegener granulomatosis. Ophthal Plast Reconstr Surg. 2006;22(1):69-71.

8. Wozel G, Barth J. Current aspects of modes of action of dapsone. Int J Dermatol. 1988;27(8):547-552.

9. Saw VP, Dart JK, Rauz S, et al. Immunosuppressive therapy for ocular mucous membrane pemphigoid strategies and outcomes. Ophthalmology. 2008;115(2):253-261.

10. Durrani K, Zakka FR, Ahmed M, Memon M, Siddique SS, Foster CS. Systemic therapy with conventional and novel immunomodulatory agents for ocular inflammatory disease. Surv Ophthalmol. 2011;56(6): $474-510$.
Clinical Ophthalmology

\section{Publish your work in this journal}

Clinical Ophthalmology is an international, peer-reviewed journal covering all subspecialties within ophthalmology. Key topics include: Optometry; Visual science; Pharmacology and drug therapy in eye diseases; Basic Sciences; Primary and Secondary eye care; Patien Safety and Quality of Care Improvements. This journal is indexed on

\section{Dovepress}

PubMed Central and CAS, and is the official journal of The Society of Clinical Ophthalmology (SCO). The manuscript management system is completely online and includes a very quick and fair peer-review system, which is all easy to use. Visit http://www.dovepress.com/ testimonials.php to read real quotes from published authors. 